\title{
TWO-DIMENSIONAL CELLULAR AUTOMATON MODEL TO SIMULATE PEDESTRIAN EVACUATION UNDER FIRE-SPREADING CONDITIONS
}

\author{
${ }^{1}$ Omar Khair Alla Alidmat, ${ }^{2}$ Ahamad Tajudin Khader \& \\ ${ }^{2}$ Fadratul Hafinaz Hassan \\ ${ }^{1} \mathrm{Al}$ al-Bayt University Jordan \\ ${ }^{2}$ Universiti Sains Malaysia, Malaysia \\ okaara14_com045@student.usm.my; tajudin@usm.my; \\ fadratul@usm.my
}

\begin{abstract}
A pedestrian evacuation under fire-spreading conditions is simulated by using a two-dimensional cellular automaton model. The proposed model presents a non-static fire-spreading behavior to avoid considerable discrepancies between reality and simulation. The proposed model adopts a circular fire front shape based on spiral fire movement. Moreover, four dynamic parameters are introduced to simplify the decision-making process of a pedestrian's movement inside the layout during fire spreading. In addition, the proposed model includes the number of victims (i.e., caught in the fire) and the number of pedestrians who were evacuated safely. By analyzing these variables, a suitable evacuation plan enabling the control of crowd movements in different situations such as fire disasters can be consequently designed.
\end{abstract}

Keywords: Cellular automaton, pedestrian simulation, circular fire front shape, spiral fire movement.

\section{INTRODUCTION}

In recent years, pedestrian evacuation in large gathering places, such as theaters, shopping centers, schools, hospitals, air terminals, and stadiums, in case of emergencies, such as fire disasters, has attracted significant attention. 
Fire accidents occur in crowded buildings may cause heavy casualties. For example, a fire at a commercial building in Luoyang, China, killed 311 people in 2000. The fire in the Mesa Redonda shopping center in Lima (Peru) killed 291 people on 29 December 2001. The 2010 Dhaka fire in the city of Dhaka (Bangladesh) on 3 June 2010 killed at least 117 people. In 2013, a nightclub fire in Brazil killed more than 233 people (Conachy, 2000; Darlington, Brocchetto, \& Ford, 2013; Nguyen, Ho, \& Zucker, 2013). This list continues to grow. Table 1 provides a list of well-known severe fire accidents in history and the corresponding casualties and losses.

Table 1

List of Notable Fire Accidents that Occurred in Years from 1997 to 2013

\begin{tabular}{|c|c|c|c|c|}
\hline Year & Casualties & Condition & Location & Reference \\
\hline 1997 & 340 & $\begin{array}{l}\text { A wind-whipped fire at a tent } \\
\text { city in Mina }\end{array}$ & Mina, Saudi Arabia & $\begin{array}{c}\text { (Almughrabi, } \\
\text { 2015) }\end{array}$ \\
\hline 2000 & 311 & $\begin{array}{l}\text { Dongdu commercial shopping } \\
\text { center fire }\end{array}$ & Luoyang, China & (Conachy, 2000) \\
\hline 2000 & 235 & Kanungu church fire & Kanungu, Uganda & (Services, 2000) \\
\hline 2001 & 291 & $\begin{array}{l}\text { Fire in Mesa Redonda } \\
\text { shopping Center }\end{array}$ & Lima (Peru) & $\begin{array}{l}\text { (Nguyen et al., } \\
\text { 2013) }\end{array}$ \\
\hline 2003 & 192 & Daegu subway fire & $\begin{array}{l}\text { Daegu, South } \\
\text { Korea }\end{array}$ & (Hong, 2004) \\
\hline 2004 & 283 & Paraguay supermarket fire & $\begin{array}{l}\text { Asunción, } \\
\text { Paraguay }\end{array}$ & (Benson, 2004) \\
\hline 2006 & 100 & $\begin{array}{l}\text { A fire that swept through large } \\
\text { tents packed with consumers } \\
\text { visiting a trade fair in } \\
\text { Victoria park }\end{array}$ & Meerut, India & (Kumar, 2006) \\
\hline 2009 & 156 & Perm Lame Horse club fire & Perm, Russia & (Valentine, 2009) \\
\hline 2010 & 117 & A fire in the city of Dhaka & $\begin{array}{c}\text { Dhaka } \\
\text { (Bangladesh) }\end{array}$ & $\begin{array}{l}\text { (Nguyen et al., } \\
\text { 2013) }\end{array}$ \\
\hline 2012 & 350 & Comayagua prison fire & $\begin{array}{l}\text { Comayagua, } \\
\text { Honduras }\end{array}$ & (Moran, 2012) \\
\hline 2013 & 233 & Nightclub fire & Brazil & $\begin{array}{l}\text { (Darlington et } \\
\text { al., 2013) }\end{array}$ \\
\hline
\end{tabular}

Such disasters always threaten human lives. In such situations, the evacuation of a large number of pedestrians from hazardous areas, under physical and temporal constraints, becomes a major issue. If the crowd fails to escape from a building in time because of wrong exit selection or the failure to avoid 
obstacles, pedestrians may be killed or injured (by fire or smoke). According to statistics (Zheng, Jia, Li, \& Zhu, 2011), 131,705 fires occurred in China in 2010, in which 1,108 people were killed and 513 people were injured. These fires resulted in direct economic losses of CNY 1.77 billion. Likewise, from 2007 to 2011, 128,959 fire accidents occurred in Malaysia, in which 413 people were killed and 380 people were injured. These disasters resulted in direct economic losses of RM 390,595.7 million (Alidmat, Hassan, \& Khader, 2015; Department of Statistics, 2012).

Given the increasing number of casualties and property losses in fire disasters, examining evacuation procedures during fire accidents is crucial to minimize the loss of life and property. Furthermore, managers of large events can employ simulation to enhance their understanding of how to control crowd movements in different situations.

This research aims to generate a fire circular front shape that has a higher accuracy than other models and to simulate the behavior of pedestrians under panic situations, such as fires, using the cellular automata (CA) model. Previous studies adopted a square fire front shape, which resulted in inaccurate fire spreading. Given the differences in the behaviors of pedestrians between panic and normal situations, the evacuation CA model was established and improved. This model analyzes the individual decision-making process and the movement of the emergent pattern when pedestrians escape from a fire scene. This model is also helpful in predicting pedestrian flow under different panic situations and in designing an evacuation plan that can control crowd movements during various emergency situations. The CA model offers practical implications in reducing the number of fatalities and injuries as a consequence of disasters.

The succeeding section provides a background of pedestrian evacuation under fire-spreading conditions and the gaps found in the current models. The third section describes the cellular automaton (CA)-based simulation model to simulate the pedestrian flow and the fire-spreading process and presents in detail the preliminary simulation results. In the last section, this paper is concluded with recommendations for subsequent improvements to the proposed simulation model.

\section{EXISTING FIRE EVACUATION MODELS}

Researchers have simulated the evacuation from the public area with fire, but they mainly assumed in their models that the fire is in static scenarios (Bo, Yong-gang, \& Cheng, 2010; Cao, Song, Liu, \& Mu, 2014; Lizhong Yang, 
Weifeng Fang, Rui Huang, \& Zhihua Deng, 2002; L. Yang, Zhao, Li, Fang, \& Fan, 2004; Y. Yang, Deng, Xie, \& Jiang, 2014) and ignored the fire's spreading feature, which is in conflict with reality and simulation. That is, the nature of fire spreading could be in contrast with the simulation run by those researchers. In addition, the proposed models by those researchers propagate inaccurate fire circular fronts that does not coincide with the real nature of fire spreading (Bo et al., 2010; Cao et al., 2014; Curiac, Banias, Volosencu, \& Pescaru, 2010; Finney, 2006; Georgoudas, Sirakoulis, \& Andreadis, 2007; Hu, Sun, Gao, Wei, \& You, 2014; Sirakoulis, Karafyllidis, \& Thanailakis, 2005; Tissera, Printista, \& Luque, 2012; Lizhong Yang et al., 2002; LZ Yang, WF Fang, R Huang, \& ZH Deng, 2002; L. Yang et al., 2004; Y. Yang et al., 2014; Zheng, Jia, Li, \& Zhu, 2011).

The existing evacuation models do not clearly show the intended direction of pedestrians in their simulations because most of them use square and circular shapes to represent each pedestrian (Bo et al., 2010; Cao et al., 2014; $\mathrm{Hu}$, Sun, Gao, Wei, \& You, 2014; Lizhong Yang et al., 2002; Y. Yang et al., 2014; Zheng, Jia, Li, \& Zhu, 2011). In this case, the intended movement direction of each pedestrian can hardly be predicted and observed, the quality of their overall movement cannot be evaluated, and their complex moving behaviors during panic situations (i.e., "chaotic" as demonstrated by the panic egress behaviors) cannot be determined. The various collective phenomena of pedestrian flow, including herding behavior, following behavior, kin behavior, competitive egress, oscillatory flows at bottlenecks, counter flow, arching, clogging, faster-is-slower, and lane formation, cannot be captured realistically when these shapes (i.e., square and circular shapes) are used to represent each pedestrian inside the layout during panic conditions.

Despite using CA models to represent the fire-spreading process, previous studies could not provide an accurate circular fire front shape. Researchers tend to assume only three starting points of fire accidents: the center, one of the corners, and near the exits (Cao et al., 2014; Curiac et al., 2010; Georgoudas et al., 2007; Muzy et al., 2006; Lizhong Yang et al., 2002; L. Yang et al., 2004; Y. Yang et al., 2014; Zheng, Jia, Li, \& Zhu, 2011; Zheng, Jia, Li, Fei, \& Zhu, 2011). These scenarios are not randomly assigned; thus, a comprehensive understanding of individual behaviors when fire accidents occur is not provided. Moreover, most fire evacuation simulations focus on evacuation time but fail to establish a mechanism to monitor the number of pedestrians who have evacuated safely, killed, or injured during the fire disaster (Bo et al., 2010; Cao et al., 2014; Curiac et al., 2010; Hu et al., 2014; Tissera et al., 2012; Lizhong Yang et al., 2002; Y. Yang et al., 2014; Zheng, Jia, Li, \& Zhu, 2011). 


\section{METHODOLOGY}

In this research, the CA model is enhanced based on existing simulation models (Hassan, Swift, \& Tucker, 2014; Hassan \& Tucker, 2010; Hassan, 2013) to represent fire spreading in a spiral mode and the pedestrian movement in a system during panic situations under the effects of a fire disaster. The fire in the proposed model spreads in a spiral manner from its starting point to one cell and among its neighboring cells based on the configuration of the Moore neighborhood at each time step. This spiral fire movement during spreading will show the fire front shape (circular) more accurately as compared with other models that adopt a square fire front shape and result in inaccurate fire spreading. Four dynamic parameters, namely, direction, empty, forward, and category, are introduced to simplify the complex and intelligent decision making of pedestrians in their movements inside the layout during fire spreading. These parameters reflect the judgments of pedestrians on their surrounding conditions and determine their choices of action, such as stepping back, moving ahead, switching lanes, and waiting, which can help us predict how pedestrian flow will behave under different circumstances.

\section{CA-Based Simulation Model}

In the current simulation, the analysis area (e.g., room, corridor, etc.) is generally divided into equal cells of a grid. The model simulates pedestrians (or walls or fire) as entities (automata) in cells. Each cell can have several values: empty, occupied by a pedestrian, occupied by fire, or a part of a wall. The walls are noted to always hold the same cells in every time step due to the walls being considered as fixed objects. Moreover, in this simulation, the exits are presented by empty cells on the wall. The simulation procedure is divided into discrete time steps. In every time step, each pedestrian can move up to eight directions and arrive to an adjacent empty cell in one time step. No two or more pedestrians are allowed to stay in one cell at the same time step. The number of moves is limited to only one cell at each simulation step $\left(V_{\max }=1\right.$ cell/time-step) for all pedestrians.

Figure 1 schematically illustrates a pedestrian flow with walls and fire on 2D grid cells. The space is modeled as grid cells. The white cells represent the empty cells that can be occupied by a pedestrian, fire, or walls, the red cells represent the fire, and the green squares represent the walls. Four types of pedestrians are considered, namely, left, right, up, and down pedestrians, which are denoted by the arrows. The up and down arrows are the pedestrians who move up and down, whereas the left and right arrows are those who move left and right. 


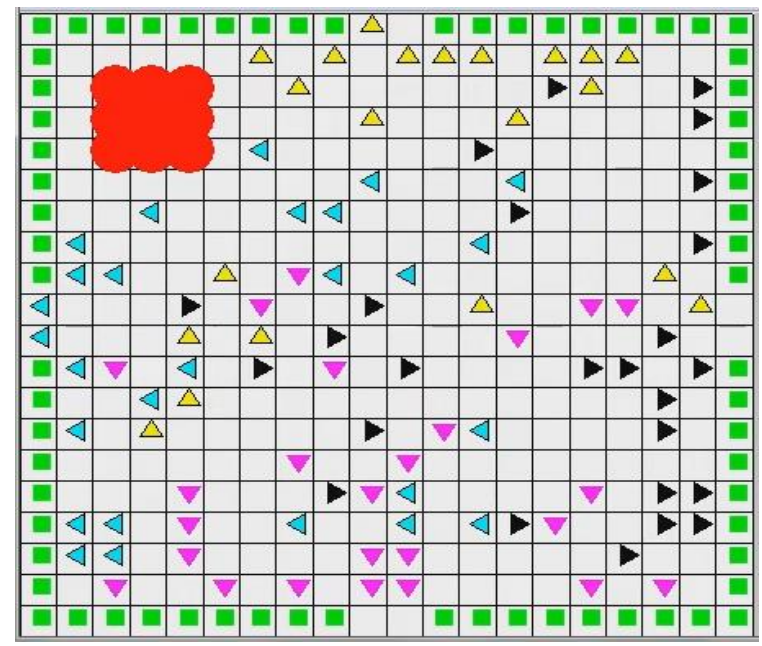

Figure 1. Pedestrian flow during fire spreading.

In this simulation, all pedestrians inside the room have the same movement target of finding the exit route under a fire-spreading condition. Therefore, each pedestrian will attempt to leave the room and find the nearest safe exit in the quickest time to avoid being exposed to combustion like $\mathrm{CO}_{2}$ for an unacceptably long period or being caught by fire. Three factors are considered in the CA pedestrian simulation model to generate more realistic results and extensive model pedestrian interactions. These factors that determine pedestrian movement to one of the neighboring cells with transition probabilities are as follows: (1) the desired direction of motion (e.g., exits), (2) interactions with other pedestrians, and (3) interaction avoidance with the infrastructure (walls, fire, etc.).

In this model, the degree of the attractiveness of the cells in the $3 \times 3$ matrix of transition probabilities are represented and computed using the following dynamic parameters developed by (Yue, Hao, Chen, \& Shao, 2007) including direction parameter, empty parameter, forward parameter, and category parameter. These four dynamic parameters are described as follows:

- $\quad$ Direction parameter $\left(D_{i j}\right)$ indicates the degree of proximity of a cell to the pedestrian destination. For example, for the up pedestrian, the destination is the upper exit of the square lattice, and the direction of movement is upward. Thus, to arrive at the destination with the shortest possible route, the pedestrian chooses the cells in the direction with a high degree of proximity to the pedestrian destination. The direction- 
parameter values employed are as follows: The value of the middle cell in the upper row in front of the pedestrian is 1 ; those of the left and right cells in the upper row in front of the pedestrian are 0.7 ; those of the three cells in the middle row are 0 ; that of the middle cell in the bottom row behind the pedestrian is -1 ; and those of the left and right cells in the bottom row behind the pedestrian are -0.7 . The up pedestrian will gain 1 unit of payoff by approaching the destination (the upper exit) with every single step. The values of elements of the directionparameter matrix are derived using the pseudo-code in Figure 2.

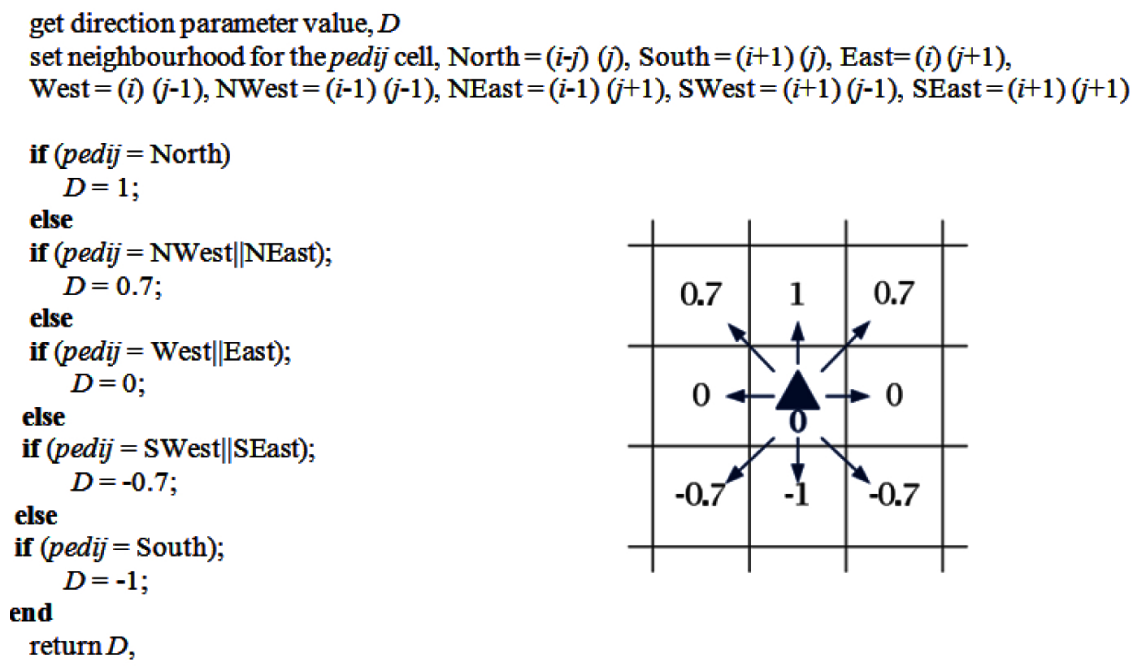

Figure 2. Pseudo-code for the direction parameter (Hassan, 2013).

- $\quad$ Empty parameter $\left(E_{i j}\right)$ indicates whether the cell is occupied or empty; therefore, the empty-parameter values reflect the influence of empty cells and occupied cells on a pedestrian. If the pedestrian moves toward an empty cell and then occupies it, the priority values of the empty cells can be derived, and the empty-parameter value of an empty cell is 1 . However, if the pedestrian chooses an occupied cell as his or her target position, the occupied cell has a strong degree of repulsiveness. Consequently, the pedestrian is more likely to neither gain the target cell nor retain the original cell, and the empty-parameter value of the occupied cell is -1 . The pedestrian may also choose not to move, and in this situation, the empty-parameter value of the core cell, i.e., the position being held by the pedestrian, is 0 . Accordingly, the values of the elements of the empty-parameter matrix are derived using the pseudo-code in Figure 3. 


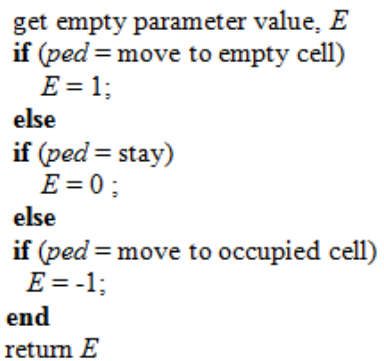

Figure 3. Pseudo-code for the empty parameter (Hassan, 2013).

- $\quad$ Forward parameter $\left(F_{i j}\right)$ describes the proportion of empty cells in the field ahead of the target position of the pedestrian. The greater the number of the empty cells is, the greater the value of the forward parameter is. If the target cell is not adjacent to the closure boundary, a vision-conscious $3 \times 5$ field (Figure 5 (a) for the pedestrian is adopted to compute the forward parameter. The vision-conscious field is hypothesized and assumed to be directly associated with the decisionmaking process of the pedestrian and can be obtained by extending five cells vertically up, including the target cell and one cell laterally on each side with the target cell in the middle. If the target cell is adjacent to the closure boundary, a $2 \times 5$ vision-conscious field (Figure 5 (b) is adopted to compute the forward parameter. The computed field can be obtained by extending five cells vertically up, including the target cell and one cell laterally on the open side. The forward-parameter value is calculated as follows: the number of occupied cells is subtracted from the number of empty cells in the vision-conscious field, and then the difference is divided by the sum of all the cells in the vision-conscious field, which reflects the mean attractiveness of the target cell to the pedestrian. The values of the elements of the forward-parameter matrix are derived using the pseudo code in Figure 4.

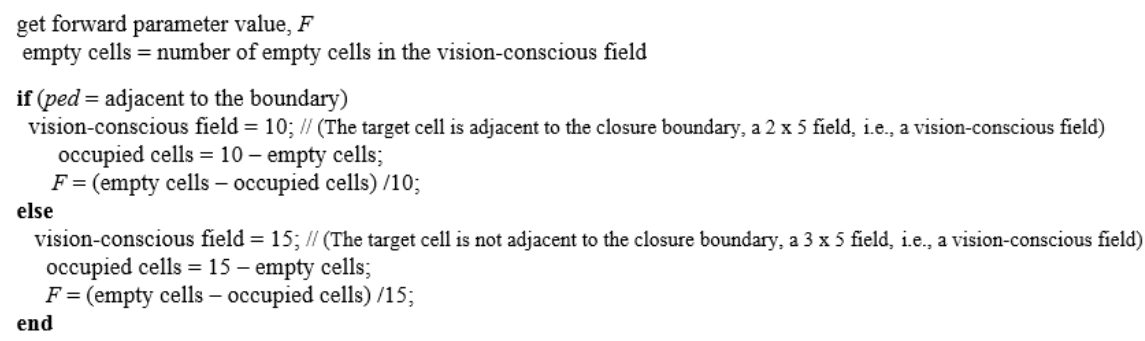

Figure 4. Pseudo-code for Forward-Parameter (Hassan, 2013). 


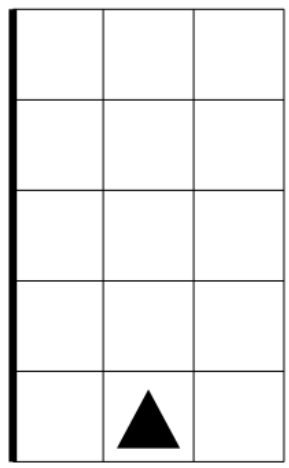

(a)

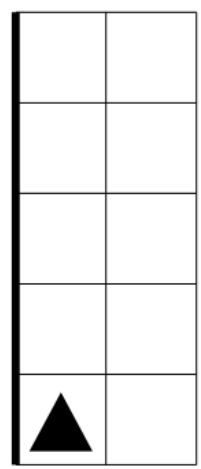

(b)

Figure 5. Schematic illustrations of the vision-conscious fields of the forward parameter (a) if the up pedestrian is not adjacent to the boundary and (b) if the up pedestrian adjacent to the boundary. Diagram adapted from (Yue et al., 2007).

- $\quad$ Category parameter $\left(C_{i j}\right)$ describes the proportion of the number of the empty cells and the pedestrians who are the same as the subject in terms of the direction of the destination in the field around his or her target position. The greater the number of pedestrians who are the same as the subject is, the greater the category-parameter value of the target cell is. If the target cell is not adjacent to the closure boundary, a $3 \times$ 5 vision-conscious field (see Figure 7 (a)) for the subject is adopted to compute the category parameter. The $3 \times 5$ vision-conscious field can be obtained by extending two cells vertically in each direction and one cell laterally on each side with the target cell at the exact center. If the target cell is adjacent to the closure boundary, a $2 \times 5$ vision-conscious field (Figure 7 (b)) is adopted to compute the category parameter. The computed field can be obtained by extending two cells vertically in each direction and one cell laterally on the open side. The category-parameter value is calculated as follows: the number of pedestrians not aiming for the destination is subtracted from the number of empty cells and pedestrians targeting the destination in the visionconscious field, and then the difference is divided by the sum of all the cells in the vision-conscious field. The values of the elements of the category-parameter matrix are derived using the pseudo-code in Figure 6. 


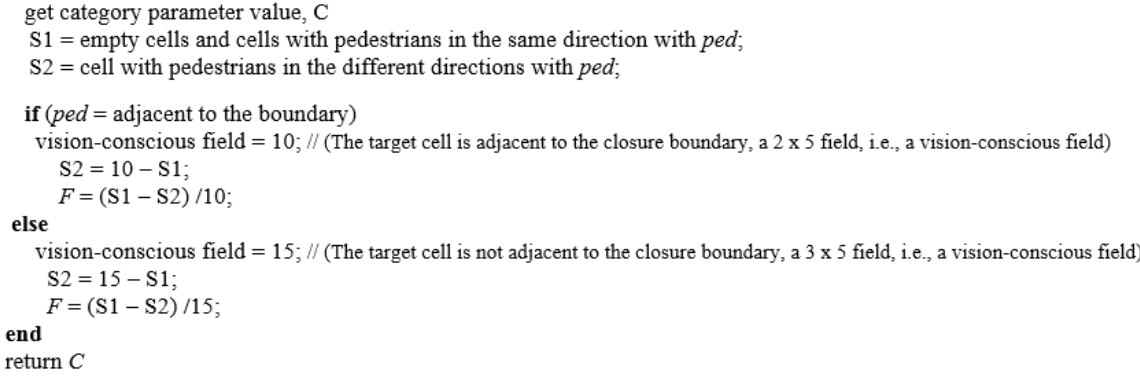

Figure 6. Pseudo-code for the category parameter (Hassan, 2013).

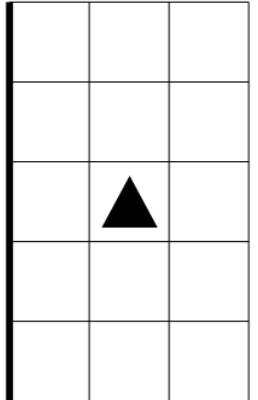

(a)

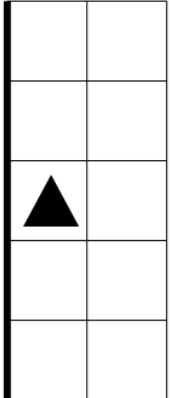

(b)

Figure 7. Schematic illustrations of the vision-conscious fields of the category parameter (a) if the up pedestrian is not adjacent to the boundary and (b) if the up pedestrian is adjacent to the boundary. Diagram adapted from (Yue et al., 2007).

In the computation of both the forward parameter and the category parameter, the proportion of the number of empty cells is considered. The proportion of the empty cells in the forward parameter reflects the attractiveness of the empty target cells to pedestrians; thus, pedestrians generally choose to move toward the front field with more empty cells, as this field provides them with more opportunities to choose from when moving toward the destination and less risks of jamming. For the Category parameter, the empty cells are considered the pedestrians who are the same as the subject, who is at the core cell in the movement field, in terms of direction. The subject deem the movement smooth in the group with pedestrians moving in the same direction or in a field containing empty cells without conflicts between pedestrians like position exchanges and head-on collisions. 
The preceding discussion clearly shows that the four dynamic parameters vary according to the conditions around the pedestrian and have values in the range $[-1,1]$. For target cells, a positive value reflects their attractiveness to the pedestrian, whereas a negative value reflects their repulsiveness to the pedestrian. The greater the absolute value is, the stronger the strength is. For pedestrians, a positive value indicates that entering a cell is advantageous in reaching their destination, whereas a negative value indicates that the position is not preferable. The greater the absolute value is, the higher the degree of advantage or disadvantage is. A value of zero indicates that the cells are neutral to pedestrians, i.e., the cells have neither attractiveness nor repulsiveness to the pedestrian, and the cells are neither advantageous nor disadvantageous to the pedestrian. These four dynamic parameters are normalized, and the maximum absolute value is 1 . The transition payoff is adopted to describe the total amount of attractiveness or advantage of a certain target cell to a pedestrian by adding the four parameters.

\section{Four-Dynamic-Parameter Model Flowchart}

Figure 8 shows the flowchart of the four-dynamic-parameter model.

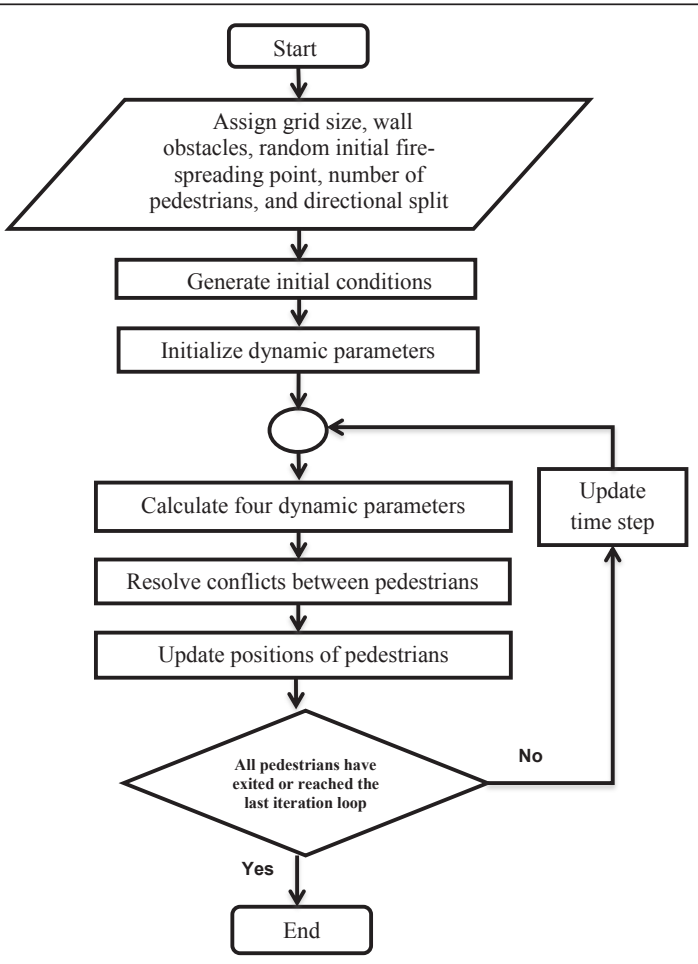

Figure 8. Four-dynamic-parameter model of pedestrian movement in a system. 
First, the model is defined on a discrete $W \times W$ cell grid in a two-dimensional system, which contains four types of pedestrians: up pedestrian, down pedestrian, right pedestrian and left pedestrian. These pedestrians are randomly distributed in the system, whose size is denoted by $W$. Each cell can be either empty or occupied by no more than one pedestrian. The simulation procedure is divided into discrete time steps. At every time step, a pedestrian can move a maximum of only one cell. The system has four boundaries: upper, bottom, left, and right. The fire starting point is initialized randomly in the system (e.g., room), and the pedestrians are randomly distributed across the system. When a pedestrian moves into the exit cell, at the next time step, he/she will leave the room and will not re-enter it. When all the pedestrians have left the room or reached the last iteration, the simulation procedure is terminated.

In the simulation, the square lattice has four exits: upper, bottom, left, and right. When the up pedestrian reaches the upper exit, he or she walks through the upper exit, and he or she will leave the room and will not re-enter the system from the bottom exit. Similarly, when the down pedestrian reaches the bottom exit, he or she walks through the bottom exit, and he or she will leave the room and will not re-enter the system from the upper exit. An analogous principle is applied to the left and right pedestrians because pedestrians share the same movement goal of finding the escape route in a room during a firespreading process.

In the Initialize dynamic parameters stage in Figure 8, the following four basic dynamic parameters are initialized: (1) direction parameter $\left(D_{i j}\right),(2)$ empty parameter $\left(E_{i j}\right),(3)$ forward parameter $\left(F_{i j}\right)$, and (4) category parameter $\left(C_{i j}\right)$. At each time step each, a pedestrian can choose to either wait at the core cell or move to one of the eight neighboring cells based on the transition payoffs $\left(P_{i j}\right)$ obtained in the previous step. The pedestrian chooses the cell with the largest value, $M$, in the matrix of transition payoff $\left(P_{i j}\right)$, i.e., $M=\max$ $(P i j)$, as his or her target position. If two target cells share the highest rank, only one of them will be chosen randomly as the target position with equal probability. The transition payoff, $P_{i j}$, is given by

$$
P_{i j}=D_{i j}+E_{i j}+F_{i j}+C_{i j}
$$

In the Resolve conflicts stage, if two or more pedestrians attempt to move to the same target position, only one of them will be chosen randomly with equal probability. The selected pedestrian moves to the corresponding cell, whereas the unselected pedestrians stay at the original position and will not move to any other cell. Moreover, a position exchange between two pedestrians is possible. At a time step, if and only if two pedestrians simultaneously choose each 
other's presently occupied cell as their target position will a mutual position exchange occur between the two pedestrians. When the position exchange takes place, the action is successfully fulfilled. In the Update positions of pedestrians stage, all the pedestrians hold new positions in the system, that is, the distribution of the pedestrians and their positions in the system change every time step over the simulation run time. Finally, if all the pedestrians have left the room or the simulation have reached the last iteration, the simulation procedure is terminated; otherwise, it will update the time step. The time evolution in the simulation is governed by discrete steps and update rules according to the principles of parallelism and locality. Parallelism means that individual cell updates are independent of each other. Locality means that, when a cell is updated, the state of a cell at time $t+1$ is a function of its individual state and the states of its neighbors at time $t$.

Therefore, the dynamic parameters are formulated to simplify the decisionmaking process for pedestrians. These parameters can reflect a pedestrian's assessment of the surrounding conditions and their choice of action. A pedestrian chooses the cell with the largest value in the matrix of transition probabilities as his or her target position. A more detailed discussion on this dynamic parameter model can be found in (Yue et al., 2007).

\section{Fire-Spreading Process Based on Spiral Fire Movement}

Researchers have examined fire evacuation (Bo et al., 2010; Cao et al., 2014; Lizhong Yang et al., 2002; L. Yang et al., 2004; Y. Yang et al., 2014) and assumed the fire in static scenarios in their models, which in conflict with reality and simulation runs. That is, the nature of fire spreading could be in contrast with the simulation run by researchers. Thus, the proposed model presents a nonstatic fire-spreading behavior to avoid considerable discrepancies between reality and simulations. Therefore, the fire in the proposed model spreads in a spiral manner from its starting point to one cell among its neighboring cells based on the configuration of the Moore neighborhood at each time step. This spiral fire movement during the spreading process will show the fire circular front more accurately in comparison with other models (Cao et al., 2014; Lizhong Yang et al., 2002; L. Yang et al., 2004; Y. Yang et al., 2014).

Figure 9 shows the pseudo-code for the spiral fire movement based on the CA model. The terms in Figure 9 are defined as follows: fdir represents the firespreading direction, lastfire represents the last burning position (cell) in the system, grid represents the number of positions (cells) in the entire system $W$ $\times W$, and burned represents the burned positions (cells) in the system. The fire starting point is initialized randomly in the system $W \times W$, and the fire then 
spreads to one of its neighboring positions. This incremental process of fire spreading generates the spiral shape of fire during the spreading process. In the pseudo-code in Figure 9, that fire spreading direction is assumed to take a left course (initial direction (fdir) = left), and the lastfire is located at the lower position of the initial fire position, as shown in Figure 10.

initial direction $($ fdir $)=$ left

initial lastfire is lower position of initial fire position

Procedure FireSpread (grid) $\{/ *$ grid $=$ number of positions in the system*/

If burned $<$ grid $\{\quad / *$ burned $=$ number of burned positions in the system */

$\operatorname{switch}($ fdir $)\{/ *$ fdir $=$ the direction of fire spread*/

case left \{

if lastfire is in the diagonal position of left-lower corner of burning area /* lastfire $=$ last of burning position */

$$
\text { fdir }=\text { up; }
$$

else \{

if lastfire is in aposition of the system \{

burn lastfire position in the system;

burned $=$ burned +1

\}

Move lastfire to the left position;

\})

Figure 9. Pseudo-code for left case of the fire-spreading process based on spiral fire movement.

The diagonal position of leftlower corner of burning area.
The fire starting point

lastfire

Figure 10. Fire-spreading process based on spiral fire movement.

As the fire-spreading direction is left, the pseudo-code in Figure 9, which determines the position of the lastfire based on the first fire position, is adopted. If the lastfire position is in the diagonal position of the lower left corner of the 
burning area (i.e., the fire starting point), the direction fdir will change from left direction to up direction and exit from the left case and enter the uppercase next iteration. Figure 10 shows the fire-spreading process based on the spiral fire movement. If the first condition in the left case is not true, another scenario will apply, that is, the code will proceed to the else branch: burn current cell (lastfire) and increase the number of the burned cells and proceed to the left side. Otherwise, the code will continue applying the left case and iteratively perform the processes described (i.e., left case first condition). This incremental process of fire spreading will generate the spiral shape of the fire during the spreading process.

\section{SIMULATION RESULTS}

Figure 11 shows that the fire-spreading process after 1 Time Step, 2 Time Steps, 3 Time Steps, 5 Time Steps, 7 Time Steps, 8 Time Steps, 10 Time Steps, 11 Time Steps, and 100 Time Steps, Respectively. This figure shows that the circular fire front shape model is more realistic than the traditional models (Cao et al., 2014; Curiac et al., 2010; Y. Yang et al., 2014). In our simulation, all pedestrians share the same movement goal of finding the escape route to the exit during a fire disaster. When all pedestrians leave the room or reach the last iteration, the simulation procedure is terminated, as shown in Figure 11.

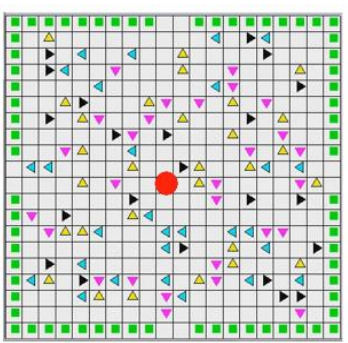

1 Time Step

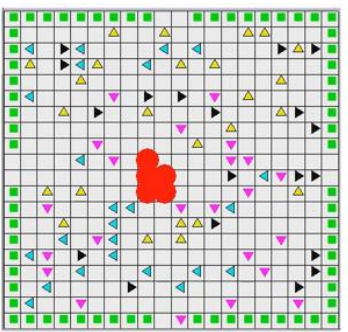

5 Time Steps

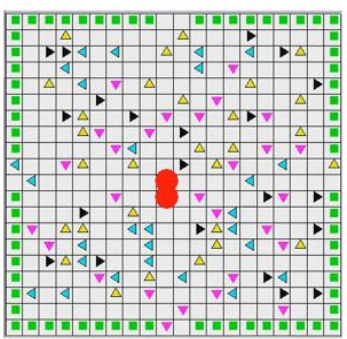

2 Time Steps

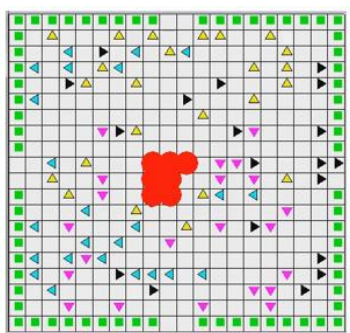

7 Time Steps

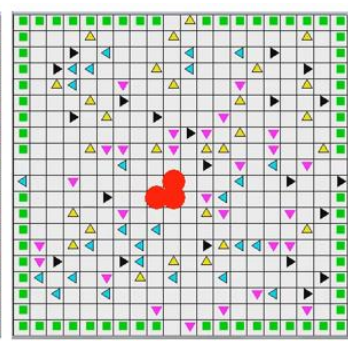

3 Time Steps

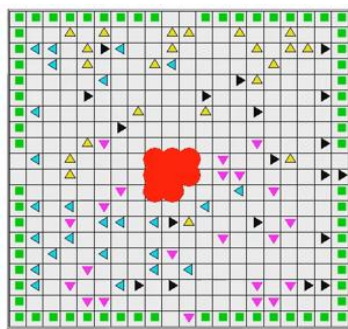

8 Time Steps 


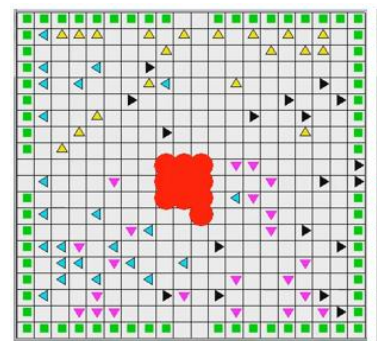

10 Time Steps

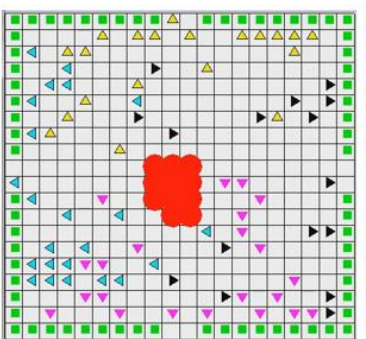

11 Time Steps

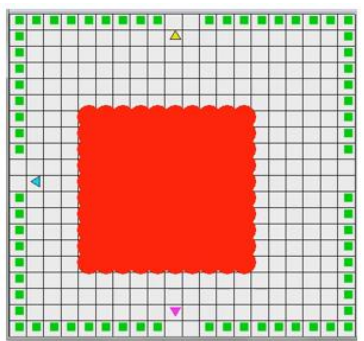

100 Time Steps

Figure 11. The Fire Spreading Process Based on the Spiral Movement Technique. After 1 Time Step, 2 Time Steps, 3 Time Steps, 5 Time Steps, 7 Time Steps, 8 Time Steps, 10 Time Steps, 11 Time Steps and 100 Time Steps, Respectively.

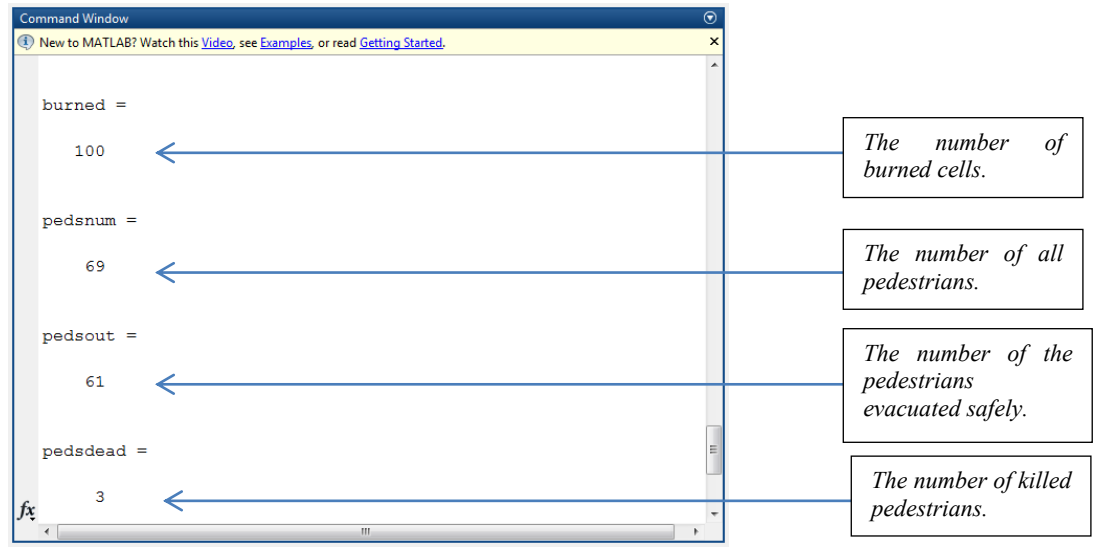

Figure 12. Fire evacuation simulation results.

Figure 12 shows the number of burned cells (burned) and the number of all pedestrians in the entire system $W \times W$ (pedsnum). The number of pedestrians who have evacuated safely (i.e., who have found the exit and left the room during the fire disaster (pedsout) and the number of pedestrians who have been killed by the fire (pedsdead) are also indicated. Information that could help predict pedestrian behavior during fire disasters can be obtained by analyzing these variables; consequently, a suitable evacuation plan enabling the control of crowd movements in different situations such as fire disasters, can be designed. 
Recently, an increasing number of models have proposed for fire evacuation. Table 2 shows a comparison of recent fire evacuation models with the proposed model.

Table 2

Comparison between Recent Fire Evacuation Models

\begin{tabular}{|c|c|c|c|c|c|c|c|}
\hline Models & $\begin{array}{l}\text { The fire } \\
\text { circular } \\
\text { front shape }\end{array}$ & $\begin{array}{l}\text { Number of the } \\
\text { victims (caught } \\
\text { by fire) }\end{array}$ & $\begin{array}{c}\text { Number of } \\
\text { the pedestrian } \\
\text { evacuated } \\
\text { safely }\end{array}$ & $\begin{array}{c}\text { Fire starting } \\
\text { point position }\end{array}$ & $\begin{array}{l}\text { Pedestrian's } \\
\text { shape }\end{array}$ & $\begin{array}{c}\text { Fire } \\
\text { spreading } \\
\text { behavior }\end{array}$ & $\begin{array}{l}\text { Pedestrians' } \\
\text { Movement } \\
\text { Model }\end{array}$ \\
\hline $\begin{array}{l}\text { Yang (Yang, Fang, } \\
\text { Huang, \& Deng, 2002) }\end{array}$ & $\begin{array}{l}\text { Inaccurate } \\
\text { (square } \\
\text { shape) }\end{array}$ & Not included & Not included & $\begin{array}{l}\text { On the } \\
\text { bottom-left } \\
\text { corner }\end{array}$ & Square & Static & CA Model \\
\hline $\begin{array}{l}\text { Yang (Yang, Zhao, Li, } \\
\text { Fang, \& Fan, 2004) }\end{array}$ & $\begin{array}{l}\text { Inaccurate } \\
\text { (square } \\
\text { shape) }\end{array}$ & Not included & Included & $\begin{array}{l}\text { On the } \\
\text { bottom-left } \\
\text { corner }\end{array}$ & Circular & Static & CA Model \\
\hline Bo (Bo et al., 2010) & Inaccurate & Not included & Not included & $\begin{array}{l}\text { On the left } \\
\text { (front of the } \\
\text { left exit) }\end{array}$ & Square & Static & $\begin{array}{l}\text { Multi-agent } \\
\text { system and } \\
\text { particle swarm } \\
\text { optimization } \\
\text { algorithm }\end{array}$ \\
\hline $\begin{array}{l}\text { Curiac (Curiac et al., } \\
2010 \text { ) }\end{array}$ & $\begin{array}{l}\text { Inaccurate } \\
\text { (square } \\
\text { shape) }\end{array}$ & Not included & Not included & $\begin{array}{l}\text { On the } \\
\text { bottom (front } \\
\text { of the left } \\
\text { exit) }\end{array}$ & Not included & Not static & CA model \\
\hline $\begin{array}{l}\text { Zheng (Zheng, Jia, Li, } \\
\text { Fei, \& Zhu, 2011) }\end{array}$ & $\begin{array}{l}\text { Inaccurate } \\
\text { (square } \\
\text { shape) }\end{array}$ & Not included & Included & $\begin{array}{l}\text { On the left } \\
\text { (front of the } \\
\text { left exit) }\end{array}$ & Circular & Not static & $\begin{array}{l}\text { Floor field } \\
\text { (FF) model }\end{array}$ \\
\hline $\begin{array}{l}\text { Zheng (Zheng, Jia, Li, } \\
\text { \& Zhu, 2011) }\end{array}$ & $\begin{array}{l}\text { Inaccurate } \\
\text { (square } \\
\text { shape) }\end{array}$ & Not included & Included & $\begin{array}{l}\text { On the left } \\
\text { (front of the } \\
\text { left exit), in } \\
\text { the middle, } \\
\text { and on the } \\
\text { right of the } \\
\text { room. }\end{array}$ & Circular & Not static & FF model \\
\hline $\begin{array}{l}\text { Tissera (Tissera et al., } \\
\text { 2012) }\end{array}$ & Inaccurate & Not included & Included & $\begin{array}{l}\text { At the } \\
\text { bottom-left } \\
\text { Corner }\end{array}$ & Circular & Not static & CA model \\
\hline $\begin{array}{l}\text { Yang (Yang, Deng, } \\
\text { Xie, \& Jiang, 2014) }\end{array}$ & $\begin{array}{l}\text { Inaccurate } \\
\text { (square } \\
\text { shape) }\end{array}$ & Not included & Not included & In the Middle & Square & Static & CA model \\
\hline $\begin{array}{l}\text { Shu-chao Ca (Cao et } \\
\text { al., 2014) }\end{array}$ & $\begin{array}{l}\text { Inaccurate } \\
\text { (square } \\
\text { shape) }\end{array}$ & Not included & Included & $\begin{array}{c}\text { On the top } \\
\text { left corner } \\
\text { and near the } \\
\text { exit }\end{array}$ & Circular & Static & FF model \\
\hline $\begin{array}{l}\text { Jun Hu (Hu et al., } \\
\text { 2014a) }\end{array}$ & $\begin{array}{l}\text { Inaccurate } \\
\text { (square } \\
\text { shape) }\end{array}$ & Not included & Not included & On the left & Black balls & Not static & FF model \\
\hline $\begin{array}{l}\text { Our Model (Alidmat, } \\
\text { Hassan, \& Khader, } \\
\text { 2015) }\end{array}$ & $\begin{array}{c}\text { More } \\
\text { accurate } \\
\text { (circular } \\
\text { front shape) }\end{array}$ & Included & Included & Randomly & Arrows & Not static & $\begin{array}{c}\text { Four-dynamic- } \\
\text { parameter } \\
\text { model }\end{array}$ \\
\hline
\end{tabular}

As shown in Table 2, the proposed model can generate the fire front shape (circular) more accurately compared with other models who adopted a square fire front shape, which resulted in an inaccurate fire spreading (Cao et al., 
2014; Curiac et al., 2010; Y. Yang et al., 2014; Zheng, Jia, Li, \& Zhu, 2011; Zheng, Jia, Li, Fei, et al., 2011). Unlike traditional models that only focus on evacuation time, the proposed model includes the number of victims (i.e., caught in the fire) and the number of pedestrians who were evacuated safely. These variables could help predict pedestrian behaviors during fire disasters and pedestrian flow behaviors under different circumstances, such as fire disasters (Bo et al., 2010; Curiac et al., 2010; Hu et al., 2014; Lizhong Yang et al., 2002; Y. Yang et al., 2014). These variables could also help establish a suitable evacuation strategy for controlling crowd movements in different situations, such as fire disasters. They could also contribute to devising a strategy that could facilitate understanding, predicting, and preventing serious problems in a crowd system, especially in big events, like pilgrimages in holy places, gatherings in places where demand is much higher than the capacity, and congestion or blockade situations wherein density may exceed the recommended value. In these situations, careful preparation, procedure, and monitoring could help minimize accidents and possibly save lives. Moreover, architectural changes and crowd management rules and procedures are among the improvements that can be implemented with the help of simulation models.

Moreover, the fire starting point initializes randomly in a system; thus, the model could facilitate a comprehensive understanding of individual behavior during fire accidents. By contrast, traditional models only assume three starting points of fire accidents: the center, one of the corners, and near the exits such as (Cao et al., 2014; L. Yang et al., 2004; Y. Yang et al., 2014; Zheng, Jia, Li, \& Zhu, 2011). Furthermore, arrows were used to represent pedestrians during the fire-evacuation process to clearly show the intended directions of pedestrians in a system and monitor how many times pedestrians could not move to their intended direction during the fire evacuation process. This innovation will help determine the quality of the overall movement of the pedestrians under different circumstances and observe pedestrian movements during fire disasters (i.e., "chaotic" as demonstrated by panic egress behaviors during a fire evacuation).

Finally, unlike traditional models such as (Bo et al., 2010; Cao et al., 2014; Lizhong Yang et al., 2002; L. Yang et al., 2004; Y. Yang et al., 2014) that assume static fire-spreading behavior, the proposed model presents a nonstatic fire-spreading behavior to avoid considerable discrepancies between reality and simulations. Therefore, the fire in the proposed model spreads in a spiral manner from its starting point to one cell among its neighboring cells based on the configuration of the Moore neighborhood at each time step. This spiral fire movement during the spreading process depicts the circular fire 
front more accurately than other models such as (Cao et al., 2014; Lizhong Yang et al., 2002; L. Yang et al., 2004; Y. Yang et al., 2014).

\section{CONCLUSION}

In this paper, a new fire evacuation model based on a two-dimensional cellular automaton model is recommended. The proposed model can generate the fire front shape (circular) more accurately as compared with other models that adopt a square fire front shape, which resulted in inaccurate fire spreading. Furthermore, the proposed model presents a non-static fire-spreading behavior to avoid considerable discrepancies between reality and simulation. Therefore, the fire in the proposed model spreads in a spiral manner from its starting point to one cell among its neighboring cells based on the configuration of the Moore neighborhood at each time step. This spiral fire movement during the spreading process will show the fire circular front more accurately in comparison with other models. Moreover, the fire starting point initializes randomly in a system; thus, the model can facilitate a comprehensive understanding of individual behavior during fire accidents. By contrast, traditional models only assume three starting points of fire accidents: the center, one of the corners, and near the exits. Furthermore, four different types of pedestrian movements were represented in arrow symbols; the left, right, up, and down arrows signified the left-moving, right-moving, up-moving, and down-moving pedestrians, respectively. In addition, the movement statistics generated from the simulation will show the number of times pedestrians move against their intended directions. This innovation will help determine the quality of the overall movement of pedestrians under different circumstances and observe pedestrian movements during fire disasters (i.e., 'chaotic' as demonstrated by the panic egress behaviors during a fire evacuation).

Four dynamic parameters, which are the direction, empty, forward, and category parameters, are introduced to simplify the complex and intelligent decision-making process of pedestrians in their movements inside the layout during the fire -spreading process, which can reflect the pedestrian judgment on the surrounding conditions and decide the pedestrian's choice of action such as back stepping, moving ahead, lane switching, stopping to wait, etc. The simulation model also includes variables such as the number of pedestrians who have been killed and who have been evacuated safely. This information, which could help predict pedestrian behavior during fire disasters, can be obtained by analyzing these variables. Therefore, a suitable evacuation plan enabling the control of crowd movements in different situations such as fire disasters can be consequently designed. 


\section{REFERENCES}

Alidmat, O. K. A., Hassan, F. H., \& Khader, A. T. (2015). Cellular automata model for pedestrian evacuation in fire spreading conditions. In Proceedings of the 5th International Conference on Computing and Informatics (pp. 293 -299). Istanbul, Turkey.

Almughrabi, N. (2015). Hundreds dead following stampede at hajj pilgrimage. Retrieved, from http://www.stratfordbeaconherald.com/2015/09/24/ hundreds-dead-following-stampede-at-hajj-pilgrimage

Benson, T. (2004). Fire kills 283 at supermarket in paraguay. Retrieved from http://www.nytimes.com/2004/08/02/world/fire-kills-283-at-super market-in-paraguay.html

Bo, Y., Yong-Gang, W., \& Cheng, W. (2010). A GIS-based simulation for occupant evacuation in an amusement building. Paper presented at the Informatics in Control, Automation and Robotics (CAR), 2010 2nd International Asia Conference on (Vol. 3, pp. 274-277). IEEE.

Cao, S.-c., Song, W.-g., Liu, X.-d., \& Mu, N. (2014). Simulation of pedestrian evacuation in a room under fire emergency. Procedia Engineering, 71, 403-409. doi: 10.1016/j.proeng.2014.04.058

Conachy, J. (2000). Christmas night fire kills 311 in central China. Retrieved from https://www.wsws.org/en/articles/2000/12/chin-d28.html

Curiac, D. I., Banias, O., Volosencu, C., \& Pescaru, D. (2010). Cellular Automata Based Simulation for Smoke and Fire Spreading in Large Buildings. Paper presented at the International Conference on Development, Energy, Environment, Economics (DEEE'10), Puerto De La Cruz, Tenerife.

Darlington, S., Brocchetto, M., \& Ford, D. (2013). Fire rips through crowded Brazil nightclub, killing 233. Retrieved from http://edition.cnn. com/2013/01/27/world/americas/brazil-nightclub-fire/

Department of Statistics, M. (2012). Malaysia, Monthly Manufacturing Statistics. CHART, 54(53.4), 53.5-54.2.

Finney, M. A. (2006). An overview of FlamMap fire modeling capabilities. Paper presented at the Fuels management-how to measure success: conference proceedings (pp. 28-30). USDA Forest Service, Rocky Mountain Research Station, Fort Collins, CO. 
Georgoudas, I. G., Sirakoulis, G. C., \& Andreadis, I. T. (2007). An intelligent cellular automaton model for crowd evacuation in fire spreading conditions. Paper presented at the Tools with Artificial Intelligence, 2007. ICTAI 2007. 19th IEEE International Conference on (Vol. 1, pp. 36-43). IEEE.

Hassan, F. H. (2013). Heuristic search methods and cellular automata modelling for layout design (Unpublished doctoral dissertation), Brunel University, School of Information Systems, Computing and Mathematics).

Hassan, F. H., \& Tucker, A. (2010). Using cellular automata pedestrian flow statistics with heuristic search to automatically design spatial layout. In Tools with Artificial Intelligence (ICTAI), 2010 22nd IEEE International Conference on (Vol. 2, pp. 32-37). IEEE.

Hassan, F. H., Swift, S., \& Tucker, A. (2014). Using Heuristic search with pedestrian simulation statistics to find feasible spatial layout design elements. Journal of Algorithms, 2(4), 86-104.

Hong, W.-H. (2004). The progress and controlling situation of Daegu Subway fire disaster. Fire Safety Science, 6, s-5--1.

Hu, J., Sun, H., Gao, G., Wei, J., \& You, L. (2014). The group evacuation behavior based on fire effect in the complicated three-dimensional space. Mathematical Problems in Engineering, 2014, 1-7. doi: $10.1155 / 2014 / 949280$

Kumar, L. (2006). Over 100 feared killed in Meerut trade fair fire. Retrieved from http://timesofindia.indiatimes.com/india/Over-100-feared-killedin-Meerut-trade-fair-fire/articleshow/1485051.cms

Moran, L. (2012). Burned alive in their cells: Hundreds died because guards couldn't find the keys as bodies fused to ceiling reveal full horror of Honduras jail blaze that killed 350. Retrieved, from http://www. dailymail.co.uk/news/article-2101959/Honduras-prison-Full-horrorjail-blaze-revealed.html

Muzy, A., Innocenti, E., Aïello, A., Santucci, J.-F., Santoni, P.-A., \& Hill, D. R. (2006). Dynamic structure cellular automata in a fire spreading application Informatics in Control, Automation and Robotics I (pp. 247-254): Springer. 
Nguyen, M. H., Ho, T. V., \& Zucker, J.-D. (2013). Integration of Smoke Effect and Blind Evacuation Strategy (SEBES) within fire evacuation simulation. Simulation Modelling Practice and Theory, 36, 44-59. doi: 10.1016/j.simpat.2013.04.001

Services, F. T. N. (2000). Blaze in uganda church kills 235 doomsday cultists. Retrieved from http://articles.chicagotribune.com/2000-03-19/news/ 0003190170_1_restoration-of-ten-commandments-sect-leader-josephkibweteere-kanungu

Sirakoulis, G. C., Karafyllidis, I., \& Thanailakis, A. (2005). A cellular automaton for the propagation of circular fronts and its applications. Engineering Applications of Artificial Intelligence, 18(6), 731-744.

Tissera, P. C., Printista, A. M., \& Luque, E. (2012). A hybrid simulation model to test behaviour designs in an emergency evacuation. Procedia Computer Science, 9, 266-275.

Valentine, C. (2009). History's top 15 worst nightclub fires. Retrieved from http://oddculture.com/historys-top-15-worst-nightclub-fires/2/

Yang, L., Fang, W., Huang, R., \& Deng, Z. (2002). Occupant evacuation model based on cellular automata in fire. Chinese Science Bulletin, 47(17), 1484-1488.

Yang, L., Fang, W., Huang, R., \& Deng, Z. (2002). Simulation of evacuation process based on cellular automaton model. Chin Sci Bull, 47, 896-901.

Yang, L., Zhao, D., Li, J., Fang, W., \& Fan, W. (2004). Simulation of evacuation behaviors in fire using spacial grid. Progress in Natural Science, 14(7), 614-618.

Yang, Y., Deng, J., Xie, C.-c., \& Jiang, Y.-t. (2014). Design and Implementation of Fire Safety Evacuation Simulation Software based on Cellular Automata Model. Procedia Engineering, 71, 364-371. doi: 10.1016/j. proeng.2014.04.052

Yue, H., Hao, H., Chen, X., \& Shao, C. (2007). Simulation of pedestrian flow on square lattice based on cellular automata model. Physica A: Statistical Mechanics and its Applications, 384(2), 567-588. 
Zheng, Y., Jia, B., Li, X.-G., \& Zhu, N. (2011). Evacuation dynamics with fire spreading based on cellular automaton. Physica A: Statistical Mechanics and its Applications, 390(18-19), 3147-3156. doi: 10.1016/j. physa.2011.04.011

Zheng, Y., Jia, B., Li, X., Fei, H., \& Zhu, N. (2011). Study of exit choice with fire based on cellular automaton. Paper presented at the Advanced Forum on Transportation of China (AFTC 2011). 